\title{
Retrograde Percutaneous Closure of a Perimemberanous Ventricular Septal Defect with an Occluder Device in a Child with Interrupted Inferior Vena Cava
}

\author{
Amal El-Sisi, MD, MRCP1', Safaa Ali, MD² \\ ${ }^{1}$ Pediatric Department of Faculty of Medicine, Cairo University Hospital, Cairo, Egypt \\ ${ }^{2}$ Pediatric Department of Faculty of Medicine, Assistant Professor, Sohag University Hospital, Souhag, Egypt
}

\begin{abstract}
Femoral venous access is the typical route for the antegrade approach to percutaneous closure of a perimemberanous ventricular septal defect (PM VSD). In this case report, we attempted percutaneous PM VSD closure in a five-year-old child with interrupted inferior vena cava (IVC) using a retrograde arterial approach. The Amplatzer Duct Occluder II was chosen due to its symmetrical design that can be deployed using either a retrograde or antegrade approach. We found the retrograde percutaneous PM VSD closure by off-label use of this device to be an easy and feasible option in this case of interrupted IVC, whereas the use of an antegrade approach would have been imprecise and potentially time-consuming.

Copyright @ 2017 Science International Corp.
\end{abstract}

\section{Key Words}

Ventricular Septal defect - Percutaneous closure • Interrupted inferior vena cava - Amplatzer Duct Occluder II

\section{Introduction}

The incidence of congenital interruption of inferior vena cava (IVC) without other visceroatrial situs abnormalities is $0.08-0.1 \%$. Interrupted IVC usually continues via the azygos system to join the superior vena cava [1]. Interrupted IVC is usually an inciden-

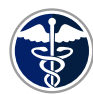

Fax +1 2037853346

E-Mail: jshd@scienceinternational.org

http://structuralheartdisease.org/ (c) 2017 Journal of Structural Heart Disease Published by Science International Corp. ISSN 2326-4004

Accessible online at: http://structuralheartdisease.org/ tal and unexpected finding during cardiac catheterization. Although managing interrupted IVC is challenging, it is not impossible through the use of certain approaches. In particular, previous reports have described the retrograde transcatheter closure of perimemberanous ventricular septal defect (PM VSD) by the off-label use of an Amplatzer Duct Occluder II (ADO II) device (St. Jude Medical, St. Paul, Minnesota) $[2,3,4]$.

\section{Case Presentation}

A five-year-old boy diagnosed with PM VSD at the age of six months was referred to our hospital for therapeutic intervention. Electrocardiography (ECG) showed left ventricular hypertrophy and cardiomegaly. Pulmonary plethora was shown by chest X-ray. Transthoracic echocardiography showed a moderate-sized PM VSD partially covered by septal aneurysm. The left ventricular opening was $5 \mathrm{~mm}$, and the right ventricular opening was $8 \mathrm{~mm}$. The aortic rim was $6 \mathrm{~mm}$. Pulmonary systolic pressure was $47 \mathrm{mmHg}$. There was a gradient of $85 \mathrm{mmHg}$ between the left and the right ventricles. The left atrium and ventricle were dilated. There was no aortic regurgitation or any other associated cardiac anomaly. Unfortunately, the subcostal window was obtained without focusing on

*Corresponding Author:

Safaa Ali

Pediatric Department of Faculty of Medicine Souhag University Hospital

Medina Street, Markaz Gerga, Sohag, Egypt

Tel. +20 1064818849; Fax: +09321 14768.; E-Mail: safaah003@gmail.com 
the IVC course.

The procedure was performed under general anesthesia with antibiotic protection (cefotiaxone $100 \mathrm{mg} / \mathrm{kg}$ body weight, administered intravenously). During cannulation, right femoral vein entry was attempted; however, the guidewire crossed the midline under fluoroscopy, consistent with inadvertent arterial puncture. A multipurpose catheter MP 2 was inserted, yielding venous waveforms, but an abnormal course was noted on fluoroscopy. Angiography was done by Pigtail 5-F, which showed interrupted IVC with azygous continuation that drained into the left superior vena cava and coronary sinus (Figure 1). After right femoral artery cannulation, one dose of heparin (100 U/kg body weight) was administered intravenously. Left ventricular angiography in $\mathrm{LAO} / 60^{\circ}$ cranial view revealed a PM VSD covered by an aneurysm with a 4-mm diameter outlet (Figure 2). The decision was made to proceed with VSD closure via a retrograde route. The procedure was monitored by transesophageal echocardiography (TEE). A guiding Judkin right JR 6-F was used for crossing the PM VSD with an angulated hydrophilic guide wire (0.035-in, Terumo Corporation, Tokyo, Ja-

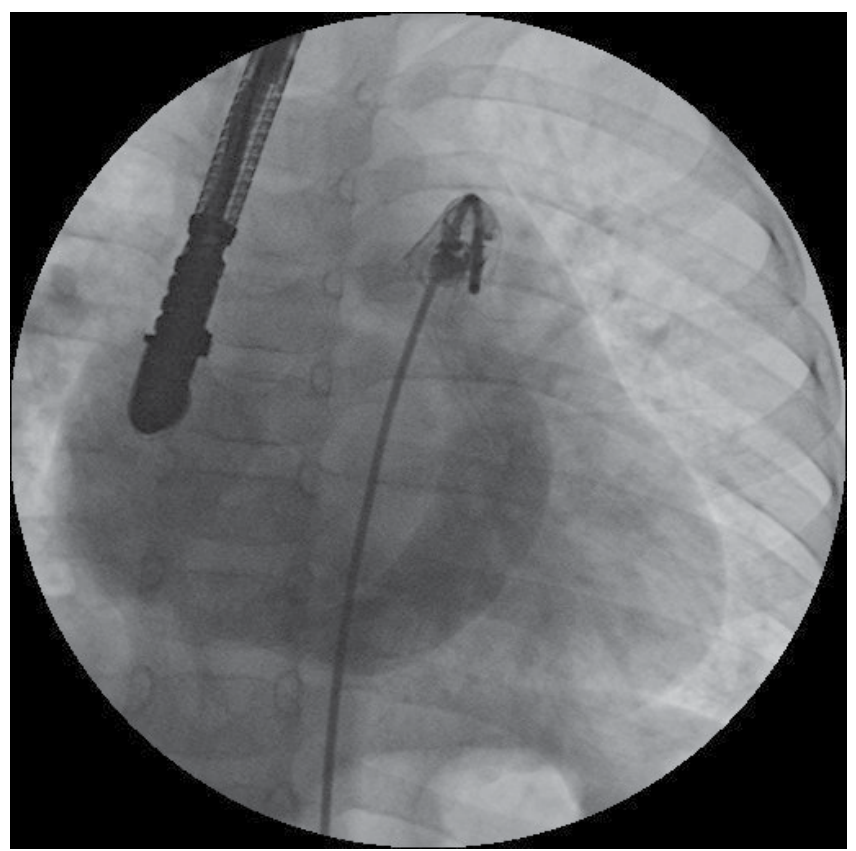

Figure 1. Angiography in the anterior-posterior view shows the course of the pigtail catheter crossing the midline, ascending via azygos continuation, and descending through the left superior vena cava and draining into the coronary sinus.

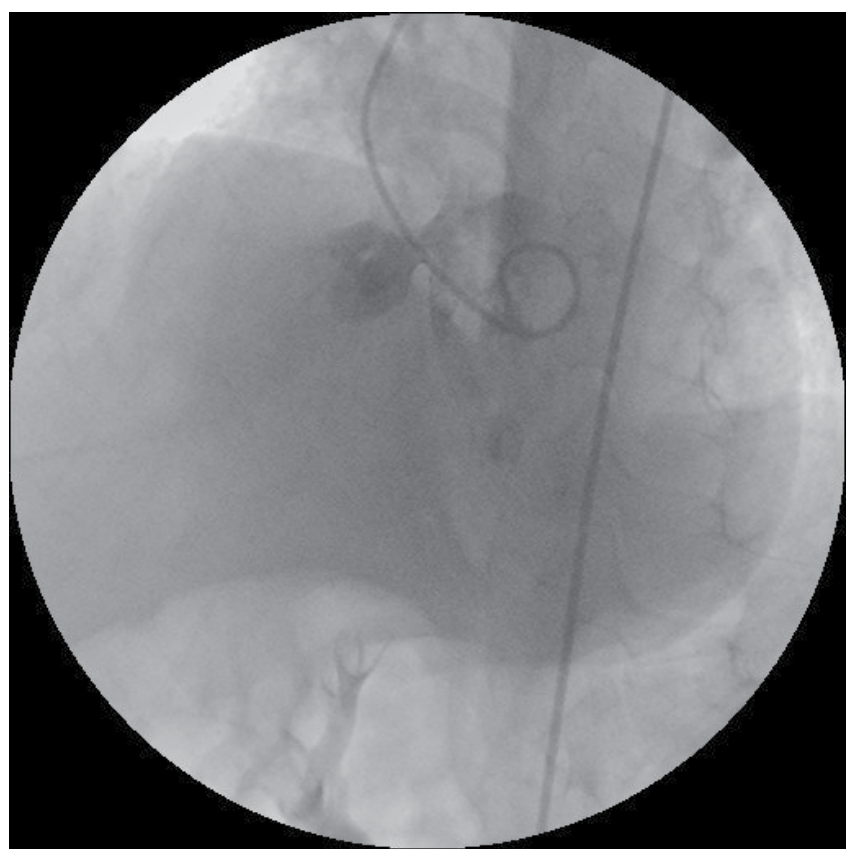

Figure 2. Angiography in $\mathrm{LAO} / 60^{\circ}$ cranial view showing the perimemberanous ventricular septal defect covered by an aneurysm with an outlet diameter of $5 \mathrm{~mm}$.

pan). The guiding JR position was secured in the right ventricle. An ADO II device (9-PDA2-06-04, AGA Medica Corp, Golden Valley, Minnesota, USA) was chosen 1 $\mathrm{mm}$ larger than the diameter of the VSD as measured by left ventricolography and TEE. The right disc was deployed in the right ventricle and then drawn until it came into contact with the interventricular septum under fluoroscopy and TEE guidance (Figures 3 and 4). The left disc was then uncovered in the left ventricle. The device was unscrewed and released after TEE confirmed a good device position and no residual shunt (Figure 5). There was no interference with tricuspid or aortic valves. The fluoroscopy time was 24 $\mathrm{min}$, and the procedure time was $90 \mathrm{~min}$.

At two-month follow-up, the child was asymptomatic with no conduction abnormality on ECG. ECG showed good positioning of the device without residual shunt and no change in pre-existent tricuspid regurgitation.

\section{Discussion}

VSD is the most common congenital heart defect, comprising approximately $20 \%$ of all such defects. 


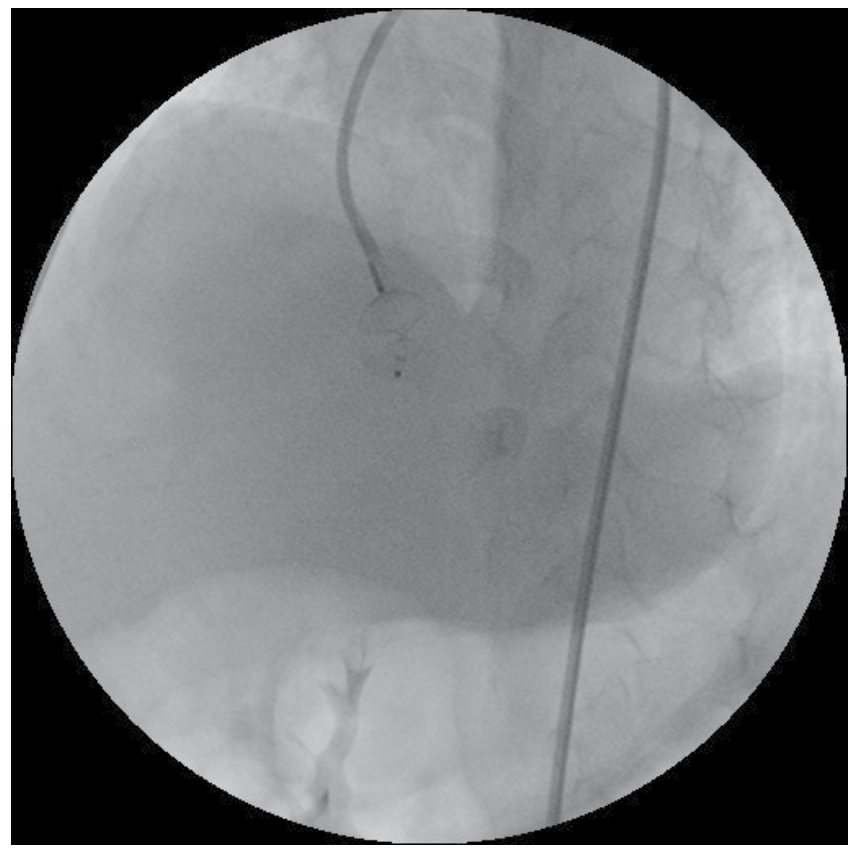

Figure 3. Transesophageal echocardiography in four-chamber view showing the perimemberanous ventricular septal defect partially covered by an aneurysm.

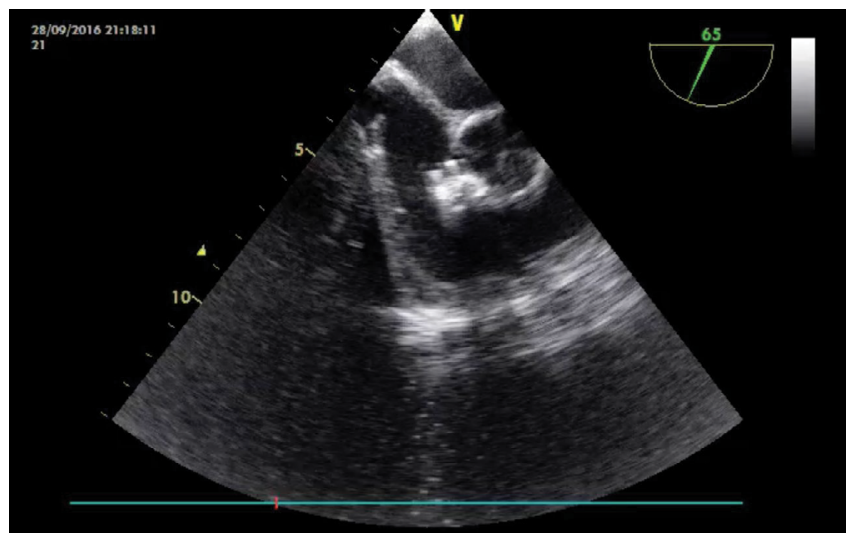

Figure 4. Transesophageal echocardiography in short axis showing good positioning of the ADO I.

With the introduction of Amplatzer devices, transcatheter closure of PM VSDs has become a well-established procedure but is associated with an unacceptable incidence of complete heart block [5]. The routine technique for percutaneous VSD closure is an antegrade approach accomplished by creating an arteriovenous loop. Here, we describe the case of a child who underwent percutaneous closure of a PM VSD using a retograde approach with an off-label ADO II in the presence of interrupted IVC and suitable anat-

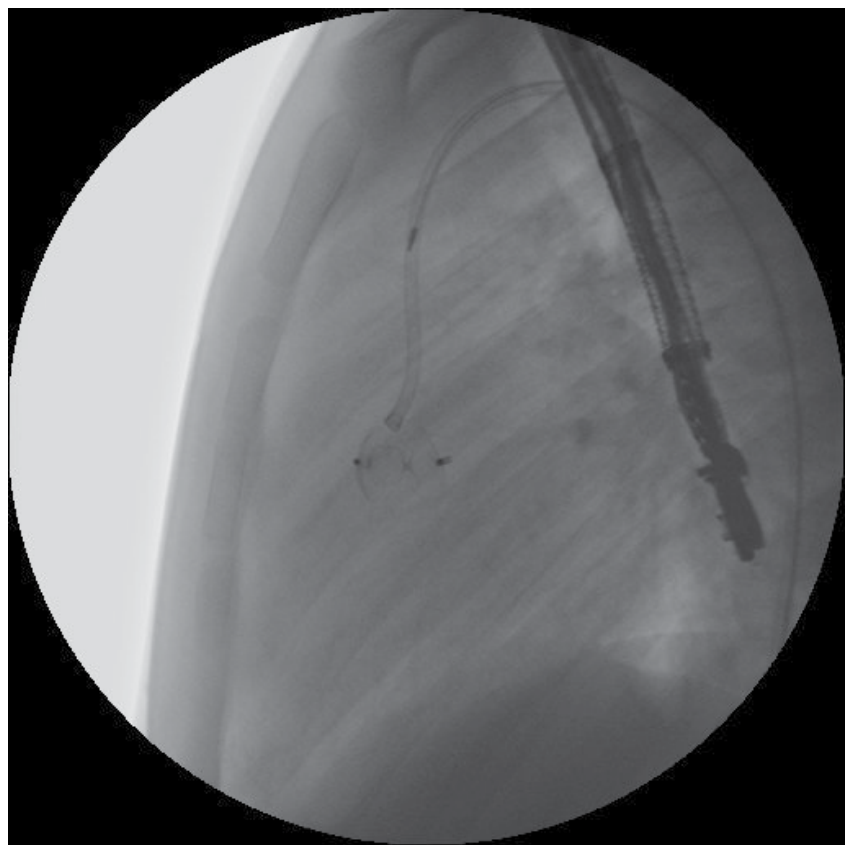

Figure 5. Cineangiography in $\mathrm{LAO} / 60^{\circ}$ cranial view showing the device completely deployed and released.

omy and diameter of PM VSD for device selection. In this situation, we believed that the transcatheter closure of the PM VSD through internal jugular access would have been imprecise, increased the duration of the procedure, and ultimately been unsuccessful. However, the transcatheter closure of ASD and patent ductus arteriosus has been established using an internal jugular approach in many previously reported cases of interrupted IVC $[7,8]$. If the size of the PM VSD had been $>6 \mathrm{~mm}$, we would not have been able to use the ADO II, as the maximum available waist diameter of the device is $6 \mathrm{~mm}$. Therefore, we would have had two options: (1) referring the patient or (2) trialing the use of the azygous vein as alternative route for an antegrade approach. Using an antegrade approach to the percutaneous closure of a PM VSD in a patient with interrupted IVC was previously described by Kawar et al. [6]. Furthermore, our experience with the percutaneous retrograde closure of a MP VSD with interventricular septum aneurysm using the ADO II is consistent with a report by Koneti et al. [2], who described successful retrograde approaches to PM VSD closure in a large group of 57 children with favorable anatomy.

In conclusion, interrupted IVC should be diag- 
nosed before planning for cardiac catheterization to choose the preferred alternative route for the procedure. Retrograde percutaneous closure of a PM VSD by off-label ADO II is considered a feasible and alternative to an antegrade approach if the size of the VSD is $<6 \mathrm{~mm}$.

\section{References}

1. Trigaux JP, Vandroogenbroek S, De Wispelaere JF, Lacrosse M, Jamart J. Congenital anomalies of the inferior vena cava and left renal vein: Evaluation with spiral CT. J Vasc Interv Radiol. 1998;9:339-345. PMID: 9540920

2. Koneti NR, Sreeram N, Penumatsa RR, Arramraj SK, Karunakar V, Trieschmann U. Transcatheter retrograde closure of perimembranous ventricular septal defects in children with the Amplatzer duct occluder II device. J Am Coll Cardiol. 2012;60:24212422. DOI: 10.1016/j.jacc.2012.08.1004

3. Zhao PJ, Yu ZQ, Gao W, Li F, Fu LJ, Liu TL, et al. Efficacy of the transcatheter closure of perimembranous and muscular ventricular septal defects with the Amplatzer duct occluder II. Zhonghua Xin Xue Guan Bing Za Zhi. 2012;40:817-820.

4. Devendran V, Koneti NR, Jesudian V. Tran- scatheter closure of multiple perimembranous ventricular septal defects with septal aneurysm using two overlapping Amplatzer Duct Occluders II. Pediatr Cardiol. 2013;34:1963-1965. DOI: 10.1007/ s00246-012-0509-z

5. Carminati M, Butera G, Chessa M, De Giovanni J, Fisher G, Gewillig M, et al. Transcatheter closure of congenital ventricular septal defects: Results of the European registry. Eur Heart J. 2007;28:2361-2368. DOI: 10.1093/eurheartj/ehm314

6. Kawar R, Mishra DK, Gautam S, Goyal BK. Device closure of ventricular septal defect by a unique technique. J Assoc Physicians India. 2016;64:93-94. PMID: 27739283

7. Narin N, Pamukcu O, Baykan A, Ozyurt A, Uzum K. Percutaneous atrial septal defect closure by using jugular venous access in a case with interrupted inferior vena cava. Postep Kardiol Interv. 2014; 38:267-269. DOI: $10.5114 /$ pwki.2014.46769

8. Patel NH, Madan TH, Panchal AM, Thakkar BM. Percutaneous closure of patent ductus arteriosus via internal jugular vein in patient with interrupted inferior vena cava. Ann Pediatr Cardiol. 2009;2:162164. DOI: $10.4103 / 0974-2069.58321$

Cite this article as: El-Sisi A, Ali S. Retrograde Percutaneous Closure of a Perimemberanous Ventricular Septal Defect with an Occluder Device in a Child with Interrupted Inferior Vena Cava. Structural Heart Disease. 2017;3(4):111-114. DOI: https://doi. org/10.12945/j.jshd.2017.0014.16 